\title{
Effect of surface area and air-drying distance on shear bond strength of etch-and-rinse adhesive
}

\author{
Farid Mohammed Sabry \\ El-Askary ${ }^{(a)}$ \\ Mohammed Salah Abdelaziz \\ Nassif ${ }^{(b)}$ \\ Andrea Mello Andrade ${ }^{(c)}$ \\ Alessandra Reis ${ }^{(d)}$ \\ Alessandro Dourado Loguercio(d)
}

\begin{abstract}
(a) Operative Dentistry Department, Faculty of Dentistry, Ain Shams University, Cairo, Egypt.
\end{abstract}

(b) Dental Biomaterials Department, Faculty of Dentistry, Ain Shams University, Cairo, Egypt.

(c) Department of Dental Materials, School of Dentistry, University of São Paulo - USP, São Paulo, SP, Brazil.

(d) Department of Restorative Dentistry, School of Dentistry, Universidade Estadual de Ponta Grossa, Ponta Grossa, PR, Brazil.

Declaration of Interests: The authors certify that they have no commercial or associative interest that represents a conflict of interest in connection with the manuscript.

\section{Corresponding Author:}

Farid Mohammed Sabry El-Askary

E-mail: faridelaskary@asfd.asu.edu.eg

Submitted: Mar 09, 2012

Accepted for publication: May 15, 2012

Last revision: May 24, 2012

\begin{abstract}
We evaluated the effects of air-drying distance and bond surface area on the shear bond strength of a 2-step etch-and-rinse adhesive. A total of 120 bovine anterior teeth were equally divided into 6 main groups based on bonding surface area. The main groups were divided into sub-groups $(\mathrm{n}=5)$ according to air-drying distance. The shear strength was determined using a universal testing machine at a crosshead speed of $0.5 \mathrm{~mm} / \mathrm{min}$. The averaged results were subjected to two-way ANOVA and Tukey's test $(\alpha=0.05)$. Two-way ANOVA testing identified no significant cross-product interactions $(\mathrm{p}>0.05)$, but the main factors of area $(\mathrm{p}<0.0001)$ and air-drying distance $(\mathrm{p}<0.00001)$ significantly affected the mean bond strength. Shorter air-drying distances improved bond strength, and increased surface area decreased the bond strength.
\end{abstract}

Descriptors: Dentin-Bonding Agents; Shear Strength; Material Testing.

\section{Introduction}

Shear and tensile tests are the most common methods of evaluating the bond strength of adhesives. The shear test is considered the most useful test, ${ }^{1}$ and, in a survey of recent literature, it was used in $26 \%$ of the papers. ${ }^{2}$ Despite this, there are disadvantages to macro-shear bond strength testing. ${ }^{3-5}$ In order to combine ease of manipulation with the ability to test multiple specimens on a single tooth, the micro-shear test was developed. ${ }^{6}$

The average bonding surface area in macro-shear tests ranges from 3.14 to $12.56 \mathrm{~mm}^{2}$ (corresponding to a $2-4 \mathrm{~mm}$ specimen diameter). The relationship between bonding area and strength has received more attention with the development of micro-tensile and micro-shear tests, ${ }^{7-10}$ and the influence of bonding area on macro-shear bond strength has been evaluated in one study. ${ }^{11}$

Excessive adhesive removal, air entrapment within the adhesive, and improper solvent evaporation ${ }^{12,13}$ are the most common clinical problems during air-drying of adhesives. These problems may be related to the air-drying distance from the dentin surface, and this distance must be considered an important clinical variable during adhesive performance testing. To our knowledge, only two studies have examined the effect of air-drying distance on bond strength. One of these studied the effect on the bond strength of a simplified etch-and-rinse adhesive, ${ }^{14}$ while the other evaluated a one-step self-etching adhesive. ${ }^{12}$ Both of these studies 
indicated that air-drying distance had a significant effect on the bond strength. In addition, due to the lack of a recommended distance in the adhesive instructions, various air-drying distances have been used in previous studies to evaporate solvent from etch-and-rinse adhesives. ${ }^{15,16}$

Therefore, the aim of this study was to evaluate the effect of very short $(1 \mathrm{~cm})$, intermediate $(5 \mathrm{~cm})$, long $(10 \mathrm{~cm})$, and very long $(20 \mathrm{~cm})$ air-drying distances on the shear bond strength of a 2 -step etchand-rinse adhesive applied to bovine teeth. The effect of bond surface area was also investigated.

\section{Methodology}

A total of 120 bovine anterior teeth were cleaned and stored in $0.1 \%$ thymol solution for not more than 1 month. Before preparation, the teeth were washed under abundant running water and the roots were removed using a diamond saw at slow speed (Isomet, Buehler, Lake Bluff, USA) with copious water cooling. The pulp was removed and the crowns were sawn in half in the mesio-distal direction. Each half was ground on wet 180 -grit SiC paper to remove the labial enamel and expose a flat dentin surface.

Following enamel removal, the pulp chambers were filled with cotton and both tooth halves were fixed using double-faced adhesive tape in a cylindrical polyvinyl chloride (PVC) mold, which was then filled with a self-curing acrylic resin (Jet, Artigos Odontológicos Clássico, São Paulo, Brazil). The molds were immersed in tap water to minimize the temperature increase during curing. The mating halves of each tooth were similarly marked. After curing of the acrylic resin, the dentin surfaces were wet-ground for 60 s using 600 -grit $\mathrm{SiC}$ paper to create a standardized smear layer. The specimens were ultrasonically cleaned in distilled water for $5 \mathrm{~min}$ prior to the bonding procedure to remove any remaining silicon carbide particles. ${ }^{17}$

\section{Specimen grouping}

The teeth were equally divided into 6 groups $(\mathrm{n}=20)$ according to the amount of surface area bonded: $0.44,0.82,1.98,3.14,7.06$, or $12.56 \mathrm{~mm}^{2}$ (corresponding to mold diameters of $0.75,1,1.59$,
2, 3, or $4 \mathrm{~mm}$ ). Each main group was divided into 4 subgroups $(\mathrm{n}=5)$ based on air-drying distances of $1,5,10$, or $20 \mathrm{~cm}$.

\section{Bonding procedure}

An etch-and-rinse 2-step adhesive (Adper Single Bond 2, 3MESPE, St. Paul, USA) and a hybrid composite material (Filtek Z250, 3MESPE, St. Paul, USA) were used in this study. The dentin surfaces were acid-etched for $15 \mathrm{~s}$, rinsed for $15 \mathrm{~s}$, and blotdried using sterile cotton, leaving the dentin surface moist. The adhesive was applied in 2 consecutive layers, gently agitated for $15 \mathrm{~s}$, and gently air-dried for $10 \mathrm{~s}$ using compressed air. ${ }^{15}$ The air-drying pressure was adjusted to 1 bar $^{12,18}$ using a pressure regulator, and the air nozzle was held at $45^{\circ}$ to the dentin surface. The adhesive was light-cured for $10 \mathrm{~s}$ using an LED curing unit (LEDition, Ivoclar Vivadent, Schaan, Liechtenstein) with an output of $600 \mathrm{~mW} / \mathrm{cm}^{2}$.

For the $0.44,0.82$, and $1.98 \mathrm{~mm}^{2}$ surface areas, each tooth received 6 specimens. For the $3.14 \mathrm{~mm}^{2}$ surface area, each tooth received 5 specimens. For $7.06 \mathrm{~mm}^{2}$, each tooth received 3 specimens. For $12.56 \mathrm{~mm}^{2}$, each tooth received 2 specimens. The specimens were distributed over the two halves using polyethylene tubes. The polyethylene tubes (TYGON Medical Tubing Formulations 54-HL, Saint Gobain Performance Plastics, Akron, USA) were applied before light-curing of the adhesive. After adhesive light curing, resin composite was carefully packed inside each tube, and a clear cellophane sheet was placed over the filled tubes and pressed gently into place. The resin samples were light-cured for $20 \mathrm{~s}$. The plastic tubes were carefully removed and the specimens were examined using a stereomicroscope at $10 \times$ magnification to identify those with evidence of air bubbles or gaps at the interface. Residual adhesive extending beyond the base of the resin cylinder was carefully removed from each sample using a blade. The specimens were stored in distilled water for $24 \mathrm{~h}$ at $37^{\circ} \mathrm{C}$.

\section{Shear bond strength testing}

The specimens were attached to a testing fixture (Odeme Equip. Odont. Ltda, Joaçaba, Brazil) which 
was then placed in a universal testing machine (Model 5565, Instron, Canton, USA). The samples were shear tested using a chisel-bladed metallic attachment with a $0.2-\mathrm{mm}$ tip for micro-shear testing and a $0.4-\mathrm{mm}$ tip for macro-shear testing. The attachment was positioned as close as possible to the composite/dentin interface. The tests were performed at a crosshead speed of $0.5 \mathrm{~mm} / \mathrm{min}$. The force required for failure (Newton) was divided by the surface area $\left(\mathrm{mm}^{2}\right)$ to determine the shear bond strength in $\mathrm{MPa}$.

\section{SEM evaluation}

The fractured specimens were mounted on aluminum stubs, sputter-coated, and examined using SEM (JEOL 5600 LVj, JEOL Ltd., Tokyo, Japan). Failure modes were evaluated and classified as mixed, cohesive, or adhesive.

\section{Statistical analysis}

Each experimental condition was represented by five teeth (10 tooth halves). Each half-tooth sup- ported 1-3 resin cylinders depending on the adhesive area. The overall bond strength values were averaged and subjected to 2-way analysis of variance (ANOVA) and Tukey's test at a significance level of 0.05 .

\section{Results}

The number of specimens undergoing each type of fracture is listed in Table 1. Figures 1-3 are micrographs of the fracture zones depicting each failure type.

Two-Way ANOVA did not identify statistically significant cross-product interactions, but both area and distance significantly affected the bond strength $(\mathrm{p}<0.00001)$. Regardless of air drying distance, significantly higher strengths were observed in the $0.44 \mathrm{~mm}^{2}$-area specimens (Table 2). Larger bond areas $\left(7.06\right.$ and $12.56 \mathrm{~mm}^{2}$ ) exhibited significantly lower bond strength. Regardless of the surface area, significantly higher bond strengths were developed in specimens dried at a distance of $1 \mathrm{~cm}$ (Table 2). Significantly lower bond strength was obtained in

Table 1 - Number of specimens for each fracture pattern in each experimental condition.

\begin{tabular}{|c|c|c|c|c|c|c|c|c|c|c|c|c|c|c|c|c|c|c|}
\hline & \multicolumn{18}{|c|}{ Area $\left(\mathrm{mm}^{2}\right)$} \\
\hline & \multicolumn{3}{|c|}{0.44} & \multicolumn{3}{|c|}{0.82} & \multicolumn{3}{|c|}{1.98} & \multicolumn{3}{|c|}{3.14} & \multicolumn{3}{|c|}{7.06} & \multicolumn{3}{|c|}{12.56} \\
\hline & \multicolumn{18}{|c|}{ Fracture Pattern } \\
\hline $\begin{array}{l}\text { Distance } \\
(\mathrm{cm})\end{array}$ & A & M & C & $A$ & $M$ & C & A & M & C & A & $M$ & $C$ & A & M & C & A & $M$ & C \\
\hline 1 & 24 & 6 & 0 & 20 & 10 & 0 & 15 & 15 & 0 & 7 & 18 & 0 & 6 & 9 & 0 & 1 & 9 & 0 \\
\hline 5 & 21 & 9 & 0 & 14 & 16 & 0 & 15 & 15 & 0 & 7 & 18 & 0 & 4 & 10 & 1 & 2 & 5 & 3 \\
\hline 10 & 24 & 6 & 0 & 16 & 14 & 0 & 11 & 19 & 0 & 9 & 16 & 0 & 7 & 7 & 1 & 3 & 6 & 1 \\
\hline 20 & 19 & 11 & 0 & 13 & 17 & 0 & 11 & 19 & 0 & 10 & 15 & 0 & 10 & 5 & 0 & 6 & 3 & 1 \\
\hline
\end{tabular}

Fracture pattern: $\mathrm{A}=$ adhesive; $\mathrm{M}=$ mixed; $\mathrm{C}=$ cohesive.

Table 2 - Means \pm standard deviation in MPa for each experimental condition.

\begin{tabular}{|c|c|c|c|c|c|c|c|}
\hline \multirow{2}{*}{ Distance $(\mathrm{cm})$} & \multicolumn{6}{|c|}{ Area $\left(\mathrm{mm}^{2}\right)$} & \multirow{2}{*}{ Total distance } \\
\hline & 0.44 & 0.82 & 1.98 & 3.14 & 7.06 & 12.56 & \\
\hline 1 & $34.2 \pm 11.7$ & $25.0 \pm 9.2$ & $23.6 \pm 8.9$ & $24.3 \pm 9.9$ & $18.0 \pm 4.6$ & $14.6 \pm 2.0$ & $23.3 \pm 10.3 a$ \\
\hline 5 & $28.4 \pm 12.5$ & $20.7 \pm 8.0$ & $20.7 \pm 10.9$ & $18.9 \pm 7.5$ & $13.3 \pm 4.3$ & $11.2 \pm 4.7$ & $18.9 \pm 9.7 b$ \\
\hline 10 & $20.1 \pm 6.4$ & $18.9 \pm 12.9$ & $19.4 \pm 4.9$ & $22.3 \pm 8.0$ & $16.5 \pm 6.7$ & $12.2 \pm 5.7$ & $18.2 \pm 8.4 b$ \\
\hline 20 & $16.3 \pm 8.9$ & $13.5 \pm 5.6$ & $12.9 \pm 6.7$ & $18.2 \pm 9.1$ & $8.2 \pm 5.8$ & $8.7 \pm 3.3$ & $13.0 \pm 8.1 \mathrm{c}$ \\
\hline Total area & $24.5 \pm 12.1 \mathrm{~A}$ & $19.5 \pm 10.1 \mathrm{~B}$ & $19.1 \pm 8.9 B$ & $20.8 \pm 8.9$ B & $13.7 \pm 6.5 \mathrm{C}$ & $11.7 \pm 4.6 \mathrm{C}$ & \\
\hline
\end{tabular}

Similar capital letters mean not statistically significant for main factor "area"; similar lowercase letters mean not statistically significant for main factor "distance". 

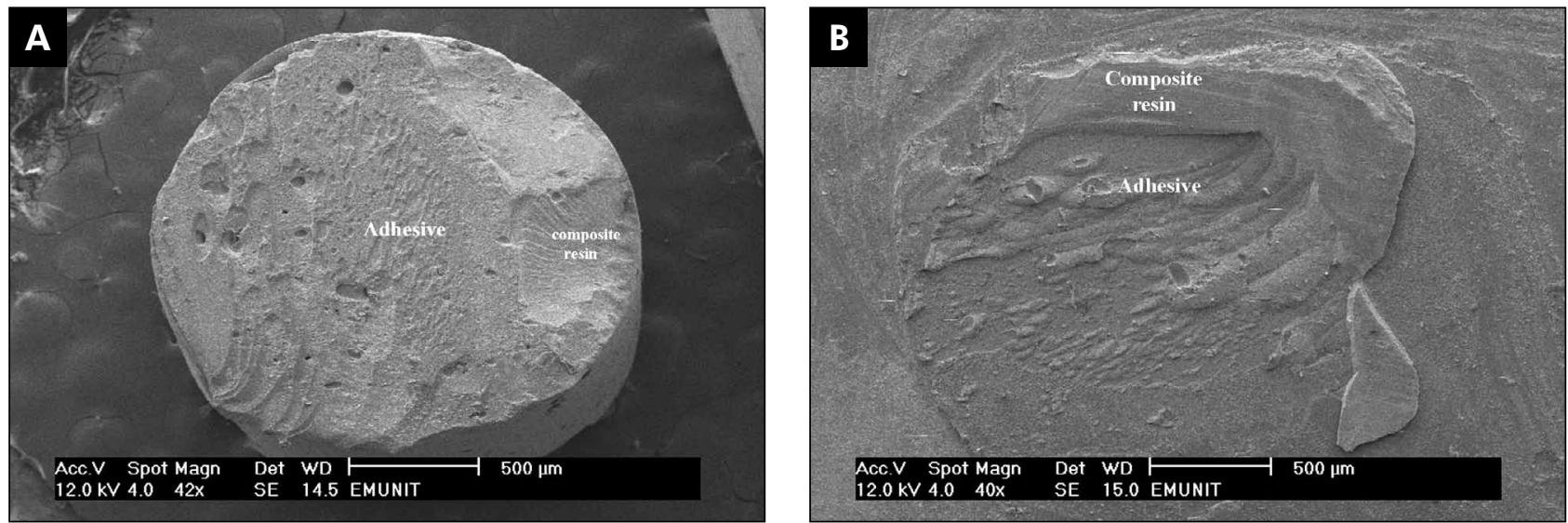

Figure 1 - SEM photomicrographs indicating cohesive failure within both the adhesive and the composite resin. A: composite resin side; $\mathbf{B}$ : dentin side.
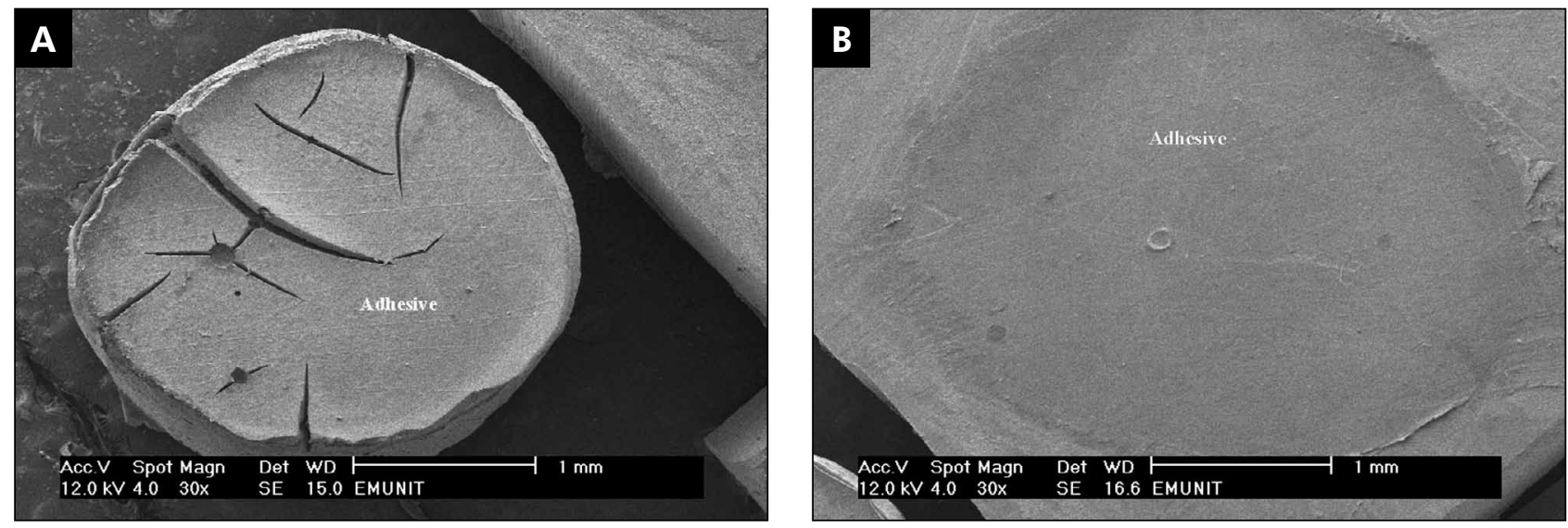

Figure 2 - SEM photomicrographs depicting adhesive failure between the adhesive and dentin. A: composite resin side with a thick cracked adhesive layer. The thick adhesive layer might be due to evaporation of solvent at a longer distance $(20 \mathrm{~cm})$ and the crack within the adhesive layer could be due to dehydration during SEM sample preparation. B: dentin side.
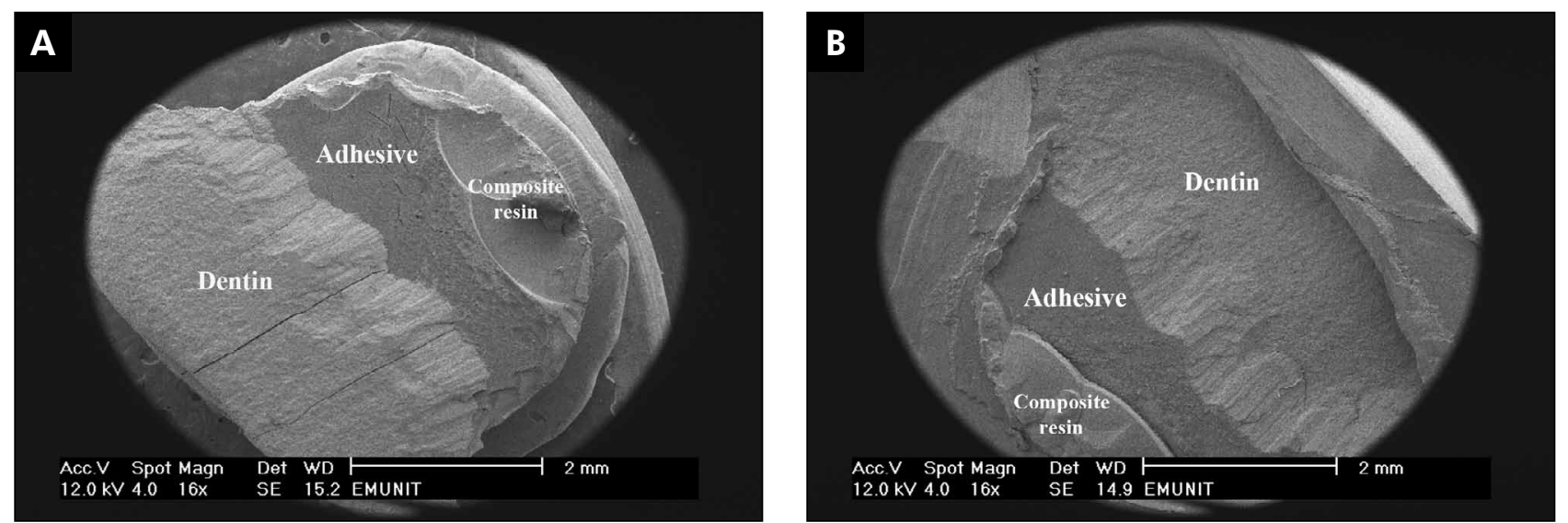

Figure 3 - SEM photomicrographs depicting a mixed failure type. A: composite resin side revealing a large area of dentin attached to the composite resin cylinder. This could be due to shear bond strength setup and the large bonding surface area $\left(12.56 \mathrm{~mm}^{2}\right)$. B: dentin side. 
specimens dried at $20 \mathrm{~cm}$.

\section{Discussion}

The rapid growth in restorative dentistry has generated an increased need for in vitro mechanical testing. The many clinical variables affecting the success of adhesive applications must also be evaluated. One important factor affecting adhesive performance is the air-drying step. Several parameters control the efficiency of air-drying, including drying time, pressure, and nozzle-tooth distance.

In this study, air-drying distance exerted a significant effect on bond strength. The adhesive contained a water/ethanol solvent, and the low vapor pressure of the water component hindered removal during the air-drying step. ${ }^{19}$ The formulation also contained HEMA, which could interfere with the removal of residual water ${ }^{20}$ and (to a lesser extent) ethanol from the adhesive. ${ }^{21}$ Increasing the air-drying distance decreased the effectiveness, particularly at low pressures. ${ }^{12}$ The reduced air-drying effectiveness resulted in decreased shear bond strength. SEM photomicrographs (Figure 2) of samples dried at long distances revealed a very thick adhesive layer. A thick adhesive layer might improve resistance to debonding stresses during composite polymerization, ${ }^{19}$ but the unnecessary increase in the thickness of the adhesive layer might be considered a weak junction at the composite/dentin interface. The excessive increase in the adhesive layer thickness could be related to the air-drying distance.

Our results were in disagreement with those of Kanca, ${ }^{14}$ who used an acetone-based 2-step etchand-rinse adhesive. Acetone has a high vapor pressure (approximately 4 times that of ethanol) ${ }^{19}$ and is therefore easier to remove. Nevertheless, future studies should be performed to evaluate the effect of air-drying distance on the bonding performance of contemporary simplified etch-and-rinse adhesives containing various solvents.

Specimens with very small surface areas $\left(0.44 \mathrm{~mm}^{2}\right)$ had significantly greater shear bond strength, and the strength decreased in larger specimens (7.06 and $12.65 \mathrm{~mm}^{2}$ ). This was similar to the findings of Phrukkanon et al. ${ }^{22}$ and Watanabe et al. ${ }^{11}$ who reported that increasing the bond surface area led to a significant decrease in bond strength. Based on results obtained using a different test methodology, El Zohairy et al. ${ }^{8}$ described an inverse relationship between the micro-tensile bond strength and the specimen dimensions. Griffith ${ }^{23}$ observed that large specimens contained a greater number of defects. Upon loading during testing, stresses were concentrated at the defects, resulting in crack formation.

The fracture analysis in the current study revealed a tendency (Table 1) toward an increase in mixed-type failures with increasing bond surface area, ranging from $26.7 \%$ for $0.44 \mathrm{~mm}^{2}$ to $57.5 \%$ for $12.56 \mathrm{~mm}^{2}$. Previous studies have reported pullout of dentin when shear tests were performed on high-strength adhesives, preventing calculation of shear bond strength from load and area measurements. ${ }^{24}$ There was no correlation between the presence of cohesive failure in dentin and bond strength. ${ }^{5}$

It is obvious that increasing the bonded surface area decreases the bond strength, and that the diameter of the bonded surface must be taken into consideration when comparing shear bond strength results between studies. Furthermore, additional efforts should be made by both manufacturers and scientists to evaluate the technique sensitivity of currently used adhesives. As the air-drying distance appears to be a very important variable, information about the optimum air-drying distance should be included in the material profiles.

\section{Conclusions}

The bond strength was adversely affected by increased air-drying distances, and the bond strength decreased with increased surface area. The failure type was relatively consistent, with mixed failure occurring more often with increasing surface area.

\section{Acknowledgment}

The authors would like to thank Dr. E. Eid, Middle East Dental Company, Egypt, and 3MESPE, St. Paul, USA, for supplying the materials used in this study. 


\section{References}

1. Braga R, Meira J, Boaro L, Xavier T. Adhesion to tooth structure: a critical review of "macro" test methods. Dent Mater. 2010 Feb;26(2):e38-49.

2. Van Meerbeek B, Peumans M, Poitevin A, Mine A, Van Ende A, Neves A, et al. Relationship between bond-strength tests and clinical outcomes. Dent Mater. 2010 Feb;26(2):e100-21.

3. Della Bona A, van Noort R. Shear vs. tensile bond strength of resin composite bonded to ceramic. J Dent Res. 1995 Sep;74(9):1591-6.

4. van Noort R, Noroozi S, Howard IC, Cardew G. A critique of bond strength measurements. J Dent. 1989 Apr;17(2):61-7.

5. Versluis A, Tantabirojn D, Douglas W. Why do shear bond strength test pulls out dentin? J Dent Res. 1997 Jun;76(6):1298307.

6. Armstrong S, Geraldeli S, Maia R, Raposo L, Soares C, Yamagawa J. Adhesion to tooth structure: A critical review of "micro" bond strength test methods. Dent Mater. 2010 Feb;26(2)e50-62.

7. Pashley D, Sano H, Ciucchi B, Yoshiyama M, Carvalho R. Adhesion testing of dentin bonding agents: a review. Dent Mater. 1995 Mar;11(2):117-25.

8. El-Zohairy A, de Gee A, de Jager N, van Ruijven N, Feilzer A. The Influence of Specimen Attachment and Dimension on Microtensile Strength. J Dent Res. 2004 May;83(5):420-4.

9. Sano H, Shono T, Sonoda H, Tatatsu T, Ciucchi B, Carvalho $\mathrm{R}$, et al. Relationship between surface area for adhesion and tensile bond strength-Evaluation of a microtensile bond test. Dent Mater.1994 Jul;10(4):236-40.

10. Shono Y, Terashita M, Pashely E, Brewer P, Pashley D. Effect of cross-sectional area on resin-enamel tensile bond strength. Dent Mater. 1997 Sep;13(5):290-95.

11. Watanabe L, Marshall G, Marshall S. Variables influence on shear bond strength testing to dentin. In: Advanced Adhesive Dentistry-3rd International Kuraray Symposium. 1999:75-90.

12. El-Askary F, Van Noort R. Effect of air-drying pressure and distance on $\mu$ TBS of a self-etching adhesive. J Adhes Dent. 2011 Apr;13(2):147-53.

13. Spreafico D, Semeraro S, Mezzanzanica D, Re D, Gagliani M, Tanaka T, et al. The effect of the air-blowing step on the technique sensitivity of four different adhesive systems. J Dent. 2006 Mar;34(3):237-44.

14. Kanca J $3^{\text {rd }}$. Wet bonding: effect of drying time and distance. Am J Dent. 1996 Dec;9(6):273-6.

15. Reis A, Klein-Jùnior C, Accorinte M, Grande R, dos Santos C, Loguercio A. Effects of adhesive temperature on the early and 6-month dentin bonding. J Dent. 2009 Oct; 37(10):791-8

16. Reis A, Klein-Júnior C, Coelho de Souza F, Stanislawczuk R, Loguercio A. The use of warm air stream for solvent evaporation: effects on the durability of resin-dentin bonds. Oper Dent. 2010 Jan-Feb, 35(1):29-36

17. El-Askary F, Nassif M. Bonding nano-filled resin modified glass ionomer to dentin using different self etch adhesives. Oper Dent. 2011 Jul-Aug;36(4):413-21.

18. De Munck J, Arita A, Shirai K, Van Landuyt K, Coutinho E, Poitevin A, et al. Microrotary fatigue resistance of a HEMAfree All-in-one adhesive bonded to dentin. J Adhes Dent. 2007 Aug;9(4):373-9.

19. Van Landuyt K, Snauwaert J, De Munck J, Peumans M, Yoshida Y, Poitevin A, et al. Systematic review of the chemical composition of contemporary dental adhesives. Biomaterials. 2007 Sep;28(26):3757-85.

20. Sadr A, Shimada Y, Tagami J. Effects of solvent drying time on micro-shear bond strength and mechanical properties of two self-etching adhesive systems. Dent Mater. 2007 Sep;23(9):1114-19.

21. Pashley E, Zhang Y, Lockwood P, Rueggeberg F, Pashley D. Effects of HEMA on water evaporation from water-HEMA mixtures. Dent Mater. 1998 Jan;14(1):6-10.

22. Phrukkanon S, Burrow M, Tyas M. Effect of cross-sectional surface area on bond strengths between resin and dentin. Dent Mater. 1998 Mar;14(2):120-28.

23. Griffith A. The phenomena of rupture and flow in solids. Philosophical Transactions of the Royal Society of London. 1921; SeriesA221:163-98.

24. Tantbiroin D, Cheng Y, Versluis A, Hodges J, Douglas W. Nominal Shear or Fracture Mechanics in the Assessment of Composite-Dentin Adhesion?. J Dent Res. 2000 Jan;79(1):418. 